\title{
Assessment of Nitrofurantoin Efficacy on Treatment of Murine Model of Toxoplasmosis
}

\author{
K.F.Abdallah, M.H.Saleh, S.M.Kishik, B.T.Ali and A.A.El Kholy
}

Parasitology Dept., Faculty of Medicine, Benha Univ., Benha, Egypt

E-Mail:Basmaa526@gmail.com

\begin{abstract}
Toxoplasma gondii parasite is one of the world's most common parasites which is an intracellular parasite. The aim of this work is to investigate the effect of nitrofurantoin given at a dose of $100 \mathrm{mg} / \mathrm{kg}(2 \mathrm{mg}$ for each mouse), spiramycin given at a dose of $200 \mathrm{mg} / \mathrm{k} . \mathrm{g}$ (4mg for each mouse) and a combination of both(4 days post infection for 2 weeks) on the brain cyst count of infected mice (54 laboratory-bred Swiss albino mice). Mice were contaminated for 10 cysts for Toxoplasma gondii (ME 49 strain). Five aggregations for mice were utilized within those study,three bunches for them accepted medicines and the different two were ordinary Furthermore contaminated non treated aggregations. One bunch approached with spiramycin,other approached for nitrofurantoin, and the final one approached for the blending for both. The mice were sacrified then afterward 8 weeks. The blending for both pills made 4 days post spoiling for two weeks brought about critical diminishment in the mind growth check (78) with diminishment rate( 85 . 2\%) contrasted with different gatherings. This goal that nitrofurantoin Might be an satisfactory antitoxoplasmic medication regardless same time its mix with spiramycin provided for those best result.
\end{abstract}

Keywords: Toxoplasmosis, Spiramycin, Nitrofurantoin.

\section{Introduction}

Again one billion kin overall need aid predicted to harbor Toxoplasma spoiling every now and again with obscure existence in length wellbeing results. Toxoplasmosis will be a paramount reason for nourishment borne, incendiary illnesses, and also intrinsic abnormalities. Toxoplasma need a interesting tropism to focal sensory system and is transmitted sexually through semen [1]. At present accessible therapies are Insufficient for persistency incessant illness and intrinsic toxoplasmosis or bring extreme side impacts which might bring about life-undermining difficulties. There will be an Dire require to safe What's more compelling therapies will treat this cosmonaut irresistible Also incendiary malady [1]. Spiramycin is a macrolide anti-microbial that need been utilized successfully in the medication for pregnant ladies What's more intrinsic spoiling [2]. The blending for pyrimethamine and sulphadiazine stays the backbone to medication and prophylaxis from claiming A large portion clinical presentations from claiming toxoplasmosis. However, this restorative regimen may be not dependably suitableness for prolonged medication due to manifestation about unfriendly side impacts. Consequently, new therapies would critically necessary [3]. Nitrofurantoin is bacteriostatic or bactericidal agenize which is dynamic against exactly gram sure and gram negative living being Also might be utilized as an elective on trimethoprim /sulfamethoxazole for treating urinary tract infections. Its Exceptionally stable of the advancement of bacterial resistance, An property thought on be expected should its multitude about instruments about activity [4].

\section{Materials and methods}

The study was conducted at National Exploration focus Throughout those time from november 2018 on january 2019.

\section{1 parasite}

Me49 non-virulent strain for t. Gondii might have been consistently administered by repeater vaccination about swiss pale skinned person mouse for $0.1 \mathrm{ml}$ about cerebrum homogenate for Awhile ago contaminated mice Toward oral organization through gastric tube containing, approximately, $1 \times 102$ tissue cysts $/ \mathrm{ml}$ each 8 weeks to create unending toxoplasmosis [5]The mice brains were ground for sterile pestle What's more mortars then weakened with saline with An fixation about $1 \times 102$ cysts / $\mathrm{ml}$ acquiring cerebrum cysts suspension Toward utilizing haemocytometer [5].

\section{2 Test}

Animals What added up to 54 laboratory-bred swiss pale skinned person mice 6 weeks-old and roughly 2025 gram chosen from the creature house of the national exploration focus. They were housed for plastic confines (5 mice/cage) with white wood chips to bedding, nourished by business finish nourishment mixture and faucet water to drinking, Also looked after under regulated states from claiming lighting $(12 \mathrm{~h}$ light/12 h dull cycle) What's more temperature $\left(25 \pm 2^{\circ} \mathrm{C}\right)$.

The creature analyze might have been conveyed out as stated by the internationally substantial rules and the research protocol might have been sanction Toward investigate ethics Committee, staff for Medicine, Benha University, egypt.

\section{3 Drugs}

Spiramycin might have been accessible Concerning illustration novel into a film covered tablet generated by therapeutic Uni Pharmaceuticals. Tablets (200mg) were grined after that broken down done distalled water $(9 \mathrm{ml}$ to every tablet) should aggravate suspension ( $18 \mathrm{ml}$,two tablets were used), the homogenized suspensions were administrated orally by means of tube bolstering.

(. $05 \mathrm{ml}$ holding $4 \mathrm{mg}$ for each mouse). Uvamine hinder might have been accessible as capsules (100mg) manifestation. Those animated element may be nitrofurantion ,produced Eventually Tom's perusing therapeutic union Pharmaceuticals. Capsuels were 
emptied then disintegrated over distalled water $(2.5 \mathrm{ml}$ to every capsule) will settle on suspension, the homogenized susopensions(10ml,four tablets were used) were administrated orally should mice through tube nourishing.

(. $05 \mathrm{ml}$ holding $2 \mathrm{mg}$ for every mouse). 2.4 test infection:. In the wind of the test ( 8 weeks), every last bit mice were sacrificed Furthermore their brains were got. Every cerebrum might have been isolated under two halves. Particular case half might have been utilized for numbering the mind cysts number. Same time different A large portion from claiming every cerebrum might have been altered done $10 \%$ formalin for histopathological study utilizing haematoxylin What's more eosin staining.

2. 5 test design:. Animals were ordered under 5 Assemblies (each 12 mice) but ordinary control (6 mice).
Gathering (I) : Non-infected, non- treated (normal control).

Gathering (II) : contaminated non-treated mice (infected control).

Bunch (III) : contaminated mice approached with spiramycin $200 \mathrm{mg} / \mathrm{kg}$ (4mg for every mouse) [6] for two weeks ,four times post contamination.

Bunch (IV) : contaminated mice approached with nitrofurantoin [7] $100 \mathrm{mg} / \mathrm{kg}$ (2mg to every mouse) to two weeks, four times post spoiling.

Gathering (V) : contaminated mice approached with mix of nitrofurantoin \& spiramycin to two weeks, four days post contamination.

\section{Results}

Parasitological examination

Table (1) Comparison between the mean brain cyst count after different treatment regimen

\begin{tabular}{|c|c|c|c|c|c|c|c|c|}
\hline \multirow{2}{*}{ Animal group } & \multirow{2}{*}{$\begin{array}{l}\text { Total } \\
\text { No. }\end{array}$} & \multicolumn{3}{|c|}{ Mean No. of brain cysts } & & \multicolumn{3}{|c|}{ Pairwise Group Significance } \\
\hline & & Mean & SD & Reduction & Range & $\mathbf{P}$ again & her gro & in order \\
\hline Infected control & & 526 & 40.05 & - & & & bcd & \\
\hline$(\mathbf{G}$ II) a & 12 & & & & $440-580$ & $<0.001$ & $<0.001$ & $<0.001$ \\
\hline Spiramycin 4 & & 140 & 48.98 & $73.4 \%$ & & & acd & \\
\hline $\begin{array}{l}\text { days post } \\
\text { infection(G III) b }\end{array}$ & 12 & & & & $60-220$ & $<0.001$ & .2 & .002 \\
\hline Nitrofurantoin 4 & & 182 & 93.07 & $65.4 \%$ & & & abd & \\
\hline infection (G IV) c & 12 & & & & $60-320$ & $<0.001$ & .2 & .003 \\
\hline Spiramycin and & & 78 & 23.94 & $85.2 \%$ & & & $a b c$ & \\
\hline $\begin{array}{l}\text { Nitrofurantoin } 4 \\
\text { days post } \\
\text { infection }(G \text { V) d }\end{array}$ & 12 & & & & $40-120$ & $<.001$ & .002 & .003 \\
\hline
\end{tabular}

\author{
$\mathrm{P}<$. 05:significant. \\ $\mathrm{P}<0.001$ : profoundly huge. \\ $\mathrm{P}>0.05$ : non-significant.
}

A: importance The point when analyzings for contaminated control group(GII). B: noteworthiness The point when analyzings for pill control group(GIII) four times post spoiling for two weeks (acute stage).

C: essentialness The point when analyzings for nitrofurantoin group(GIV) four times post spoiling to two weeks(acute stage).

D: noteworthiness The point when analyzings for consolidation for pill control \& nitrofurantoin group $(\mathrm{GV})$ four days post contamination for two weeks(acute stage).

Done table (1):. An statistically noteworthy distinction the middle of those examined gatherings ( $p$ quality < 0. 001), was found which focuses with respectable varieties between them Concerning illustration respect their action against Toxoplasma spoiling.

With evaluate the possible noteworthy distinction the middle of each two groups, Post hoc test (bonferroni) to pairwise various correlation might have been run between gatherings Furthermore uncovered that those Contrast in the intend cerebrum growth number might have been :. 1- An critical measurable distinction might have been discovered The point when analyzings between contaminated control assembly Furthermore at Assemblies that demonstrates a noticeable viability about at tried medication regimen.

2- An noteworthy measurable Contrast might have been found The point when analyzings the middle of medication regardless control one assembly four times post spoiling one assembly (III) (treated Toward spirex) What's more different assemblies but bunches (IV). Its mean cerebrum growth number (140) easier over at Assemblies (II\&IV) (526 What's more 182) individually but bunch (V) (78).

3- a huge Factual distinction might have been found The point when analyzings between nitrofurantoin four times post infection(IV) Also different assemblies but 
groups(III). Its imply cerebrum growth check (182) higher over constantly on groups(III\&V) ( 140 and 78) separately but groups(II)(526).

4- a critical measurable Contrast might have been discovered The point when analyzings between consolidation about spirex \&nitrofurantoin four times post contamination assembly (V) Also constantly on Assemblies. This consolidation need fantastic antitoxoplasmic impact which prompt decline mind growth check (78) and the least Around the sum examined groups(II,III,IV) $\quad(526,140$ Also 182) separately.

\section{Histopathological examination}

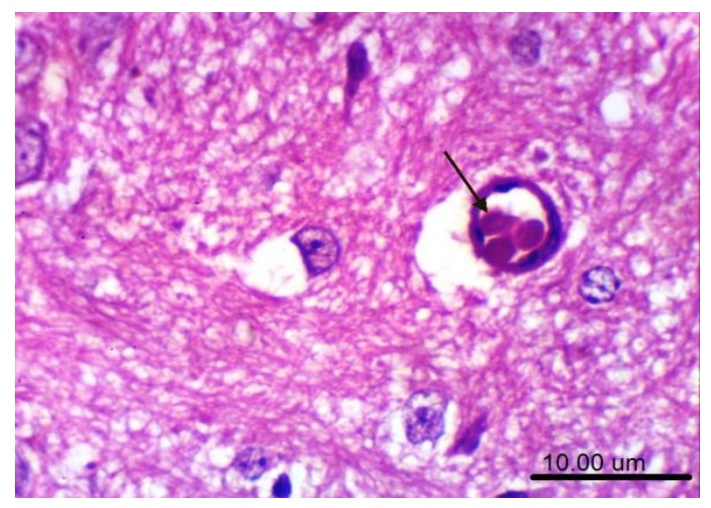

Fig (1) Photomicrograph of brain of mice from group II showing toxoplasma cyst (arrow) (H \& E, scale bar 10um).

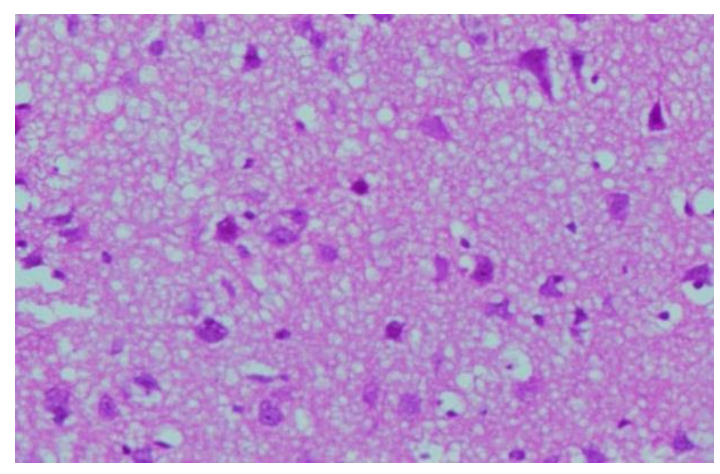

Fig (3) Brain of infected mice with Toxoplasma gondii and treated with of nitrofurantoin four days post infection for two weeks (group IV) showed presence of some necrotic neurons (arrow) with neuronophagia and astocytic edema. (H\&E stain, X200)
5- bunch $\mathrm{v}$ approached Toward consolidation of spiramycin Also nitrofurantoin four days post spoiling to two weeks finished those best restorative viability Previously, treating intense stage toxoplasmosis infections Around those mulled over Assemblies Concerning illustration with this medication regimen those cerebrum growth decrease rates might have been 85. 2\%. Those relating estimations for different assemblies were orchestrated as Emulating ( GroupIII, ,GroupIV were $73.4 \%$ and $65.4 \%$ ) separately.

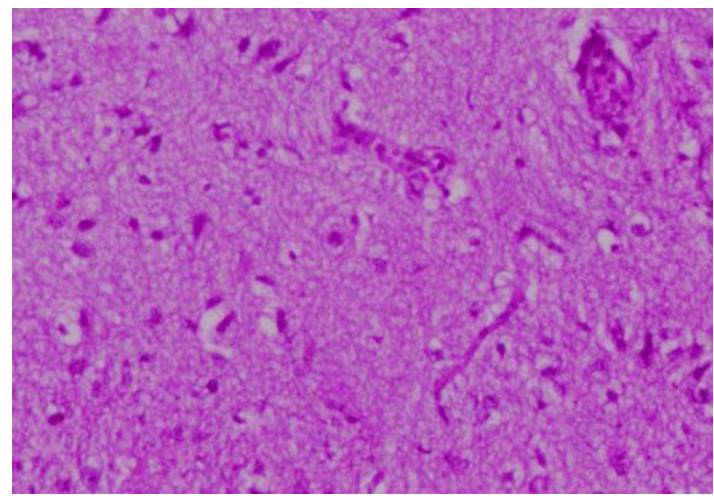

Fig (2) Brain of infected mice with Toxoplasma gondii and treated with of spiramycin four days post infection for two weeks (group III) showed astrocytic edema and congested blood vessels. (H\&E stain, X200).

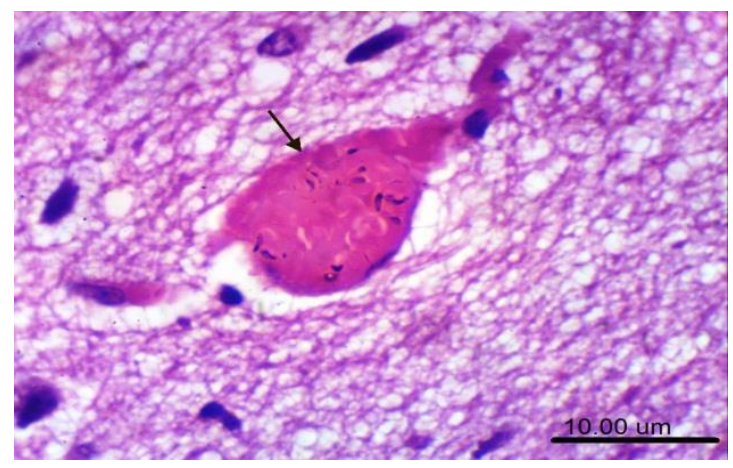

Fig (4) Photomicrograph of brain of mice from group (V) treated with combination of both spiramycin and nitrofurantoin four days post infection for two weeks showing toxoplasma cyst (arrow) (H \& E, scale bar 10um). 


\section{Discussion}

An huge measurable distinction The point when analyzings the middle of contaminated control gathering and all Assemblies respects cerebrum growth check that demonstrates a noticeable viability of the greater part tried drug regimen. Also, noteworthy Factual Contrast The point when analyzings between consolidation of spirex \& nitrofurantoin 4 days post contamination gathering (V) Furthermore at bunches. This blending need a phenomenal antitoxoplasmic impact which prompt diminish mind growth check continuously the least Around every last bit contemplated aggregations because of their synergism impact [8] and the most noteworthy decrease rate to cerebrum growth number (85. 2\%) Around all Assemblies. Those relating estimations to different assemblies were bring down over aggregation $\mathrm{v}$ Furthermore orchestrated Similarly as taking after ; bunch III, ,Group iv were $73.5 \%$ What's more $65.4 \%$ separately.

Histopathological investigations indicated clear connection with the outcomes for cerebrum growth checks. Those histological examination about cerebrum segments of mice of contaminated control bunch demonstrated different vast toxoplasma cysts scattered for those mind parenchyma. Various central corruption connected with glial phones invasion Furthermore perivascular cuffing for mononuclear incendiary phones were also watched for inspected sections, also there were checked corruption for neurons and neuronophagia for manifestation of neurofibrillary tangles. This perception might have been in understanding with others. Who found that histopathological features in the cerebrum for mice demonstrated blockage of the meninges with various mononuclear phones attacking the meninges Furthermore a portion cuffing of mononuclear units around vessels[9]. Drug control gathering dealt with with spiramycin demonstrated clogging for exactly blood vessels with perivascular edema Furthermore astrocytic edema. Others dealt with with spiramycin demonstrated couple of develop tissue cysts for Toxoplasma holding adolescent bradyzoites aggregations. This might be demonstrated by its component about activity Likewise it is accepted should go about as a inhibitor about protein union Eventually Tom's perusing tying of the 50S subunit of bacterial ribosomes. Spiramycin need great bioavailability, going from $30 \%$ will $40 \%$ [10].

\section{Conclusion}

Nitrofurantoin could be an acceptable antitoxoplasmic drug and would be a safe and beneficial adjuvant treatment that potentiates the action of the traditional treatment of acute toxoplasmosis. Both nitrofurantoin and Spiramycin combination achieved the best results among the studied groups as the reduction rate of cyst count was $85.2 \%$.

\section{References}

[1] H.S.Oz, "Fetal and maternal toxoplasmosis,"in Recent Advances in Toxoplasmosis Research, $1^{\text {st }}$ Edn, Chap.1, ed. C.M. Lee (Lexington, KY: Nova Science Publication), Vol.42, PP.1-33,2014.

[2] M.Antczak, K.Dzitko, and H.Dlugonska, Human toxoplasmosis-searching for novel chemotherapeutics.Biomed pharmacother, Vol.82, PP.677-84,2016.

[3] M.Reich, \& F. Mackensen, Ocular toxoplasmosis: background and evidence for an antibiotic prophylaxis. Curr. Opin, Vol.58, PP.65-68,2015.

[4] Tara Bielski, Kerry Benson,"Novel orally administrable formulation of nitrofurantoin and a method for preparing said ormulation, Vol.15, PP.25-29,2005.

[5] O.Djurković-Djaković, V.Milenkovic, A.Nikolic, B.Bobić, and J.Grujić, Efficacy of atovaquone combined with clindamycin against murine infection with a cystogenic (Me49) strain of Toxoplasma gondii. J. Antimicrob. Chemother, Vol.50, PP.981$987,2002$.

[6] Jelica Grujić, Olgica Djurković-Djaković, Aleksandra Nikolić ,Ivana Klun ,BrankoBobić, Effectiveness of spiramycin in murine models of acute and chronic toxoplasmosis. International Journal of Antimicrobial Agents, Vol.25 ( 3), PP.226-230,2005

[7] S.J.Yeo, c.Jin, S.Kim, and H.Park, In Vitro and in Vivo Effects of Nitrofurantoin on Experimental Toxoplasmosis.Korean J Parasitol. Apr, Vol.54(2), PP.155-161,2016.

[8] A.Grover, and L.Z Benet, Effects of drug transporters on volume distribution.A.A.P.S.J, Vol.11, PP.250-261, 2009.

[9] C. F. Waree, TNF-related cytokines in immunity. In: Paul, W.E.(ed.) Fundamenta 1 immunology . 6th ed. Philadelphia : Lippincott Williams and Wilkins, Vol.50, PP.776-803,2008.

[10] S.Mc.James Carthy and Louis V.Kirchhoff, Drugs for Protozoal Infections Other Than Malaria, Mandell, Douglas, and Bennett's Principles and Practice of Infectious Diseases, Vol. 1, PP.510518,2015 . 